\title{
Transactions
}

Cite this: Dalton Trans., 2012, 41, 11085

www.rsc.org/dalton

PAPER

\section{Influence of counterions on the structure of bis(oxazoline)copper(II) complexes; an EPR and ENDOR investigation $\uparrow$}

\author{
Mari Elena Owen, Emma Carter,* Graham J. Hutchings, Benjamin D. Ward and Damien M. Murphy*
}

Received 13th June 2012, Accepted 6th July 2012

DOI: $10.1039 / \mathrm{c} 2 \mathrm{dt} 31273 \mathrm{e}$

X- and Q-band EPR and ENDOR spectroscopy was used to study the structure of a series of heteroleptic and homoleptic copper bis(oxazoline) complexes, based on the (-)-2,2'-isopropylidenebis[(4S)-4-phenyl2-oxazoline] ligand and bearing different counterions (chloride versus triflate); labelled [Cu $\left.{ }^{\mathrm{II}}(\mathbf{1 a}-\mathbf{c})\right]$. The geometry of the two heteroleptic complexes, $\left[\mathrm{Cu}^{\mathrm{II}}(\mathbf{1 a})\right]$ and $\left[\mathrm{Cu}^{\mathrm{II}}(\mathbf{1} \mathbf{c})\right]$, depended on the choice of counterion. Formation of the homoleptic complex was only evident when the $\mathrm{Cu}^{\mathrm{II}}(\mathrm{OTf})_{2}$ salt was used $\left(\mathrm{Cu}^{\mathrm{II}}(\mathrm{Cl})_{2}\right.$ inhibited the transformation from heteroleptic to homoleptic complexes). The hyperfine and quadrupole parameters for the surrounding ligand nuclei were determined by ENDOR. Well resolved ${ }^{19} \mathrm{~F}$ and ${ }^{1} \mathrm{H}$ couplings confirmed the presence of both coordinated water and $\mathrm{TfO}^{-}$counterions in $[\mathrm{Cu}(\mathbf{1 a})]$.

\section{Introduction}

Enantioselective asymmetric synthesis involves the preparation of chiral compounds with well defined three-dimensional stereochemistry. ${ }^{1-4}$ These enantiomerically pure compounds are vital for many applications, for example, in the pharmaceutical industry, for vitamins and flavourings and in nonlinear optical and liquid crystalline materials to name a few. A wide range of synthetic catalysts are now available based on a diverse class of organic ligands which can achieve excellent levels of enantioselectivity for many different reaction types. In several of these cases, the enantioselective reaction is catalyzed by chiral Lewis acid complexes, often based on main group or transition metal salts coordinated to the chiral organic ligand. ${ }^{3}$

Among the many available ligands to promote these asymmetric reactions, the chiral bis(oxazoline) ligands (commonly abbreviated to BOX) have been widely used (Scheme 1). ${ }^{5,6}$ In particular the $\mathrm{Cu}^{\mathrm{II}}$ bis(oxazoline) complexes have been successfully used for a diverse range of reactions including the DielsAlder reaction, ${ }^{7-16}$ cyclopropanation, ${ }^{17-20}$ and aziridination. ${ }^{21-23}$ To date, a vast array of BOX ligands have been developed in order to optimise and tune the catalytic performance. ${ }^{24}$ The ability of the metal centre, including zinc, nickel, iron and copper, to coordinate through bidentate, tridentate or tetradentate coordination affords opportunities to tune the ligand to the required catalytic reaction. ${ }^{1,24}$ Upon coordination of the bidentate ligand, an almost planar metallacycle is formed. This, along with the presence of the pendent five-membered rings, are important

School of Chemistry, Cardiff University, Main Building, Park Place, Cardiff CF10 3AT, UK.E-mail: CarterE4@cardiff.ac.uk,

MurphyDM@cardiff.ac.uk

$\dagger$ Electronic supplementary information (ESI) available: X-band EPR of $\mathrm{CuCl}_{2}$ : BOX, Q-band ${ }^{14} \mathrm{~N}$ ENDOR of $[\mathrm{Cu}(\mathbf{1} \mathbf{b})]$, Q-band ${ }^{14} \mathrm{~N}$ ENDOR of $[\mathrm{Cu}(\mathbf{1 c})]$. See DOI: $10.1039 / \mathrm{c} 2 \mathrm{dt} 31273 \mathrm{e}$

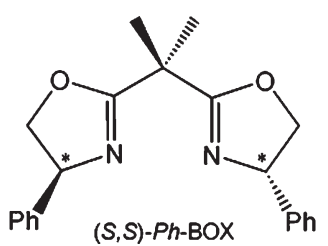

(1)

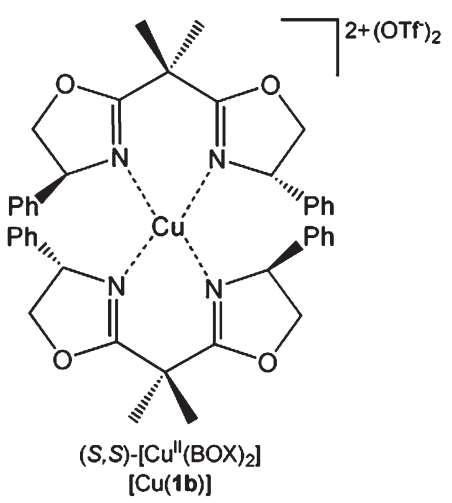

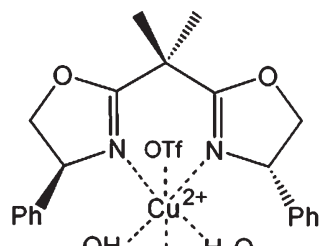

$\mathrm{OH}_{2} \mathrm{OTf} \mathrm{H}_{2} \mathrm{O}$

$(\mathrm{S}, \mathrm{S})-[\mathrm{Cu} \text { (IBOX)](OTf })_{2}\left(\mathrm{H}_{2} \mathrm{O}\right)_{2}$ [Cu(1a)]

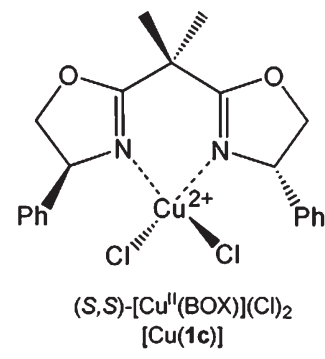

Scheme 1 Structures of the bis(oxazoline) complexes used in this study. Schematic illustration of the $\left[\mathrm{Cu}^{\mathrm{II}}(\mathbf{1 a}-\mathbf{c})\right]$ complexes as identified by EPR/ENDOR.

factors in limiting the flexibility of these ligand systems. ${ }^{4,14}$ Ligands with a single carbon nucleus bridging between the oxazoline rings are the most commonly employed (Scheme 1), but alternatives have been explored in which adjustments have been made to the nature, size and flexibility of the link between the two oxazoline rings. ${ }^{25}$

Since the $\mathrm{Cu}^{\mathrm{II}} \mathrm{BOX}$ complexes are usually generated in situ by reacting the chiral BOX ligand with a suitable $\mathrm{Cu}^{\mathrm{II}}$ salt, the choice of counterion is reported to have a large influence on the resulting enantioselectivities and yields. For example, Fraile 
et al., ${ }^{26}$ demonstrated a significant decrease in selectivity in the reaction of styrene with ethyl diazoacetate when triflate counterions are replaced by chlorides, while Evans et al., ${ }^{18,21}$ showed that highly electronegative counterions $\left(\mathrm{Cl}^{-}, \mathrm{Br}^{-}\right)$are a design prerequisite for efficient asymmetric aziridination. Furthermore Jørgensen, ${ }^{8}$ reported that the combination of counterion and solvent must be optimised to achieve the highest overall rates and enantioselectivities. This was exemplified by the reported 20-fold greater reactivity and superior enantioselectivity for cationic $\left[\mathrm{Cu}^{\mathrm{II}}(\mathrm{BOX})\right]\left(\mathrm{SbF}_{6}\right)_{2}$ compared to the triflate counterparts. $^{27}$

Despite the importance of the counterion in modulating the catalytic activity, few experimental techniques can probe such influences in solution. For paramagnetic $\mathrm{Cu}^{\mathrm{II}}$ based BOX complexes, EPR and the related hyperfine techniques such as ENDOR are an ideal method to examine any structural or electronic perturbations to the metal-complex caused by the different counterions. A limited number of papers have been reported on the CW EPR spectra of $\mathrm{Cu}^{\mathrm{II}}(\mathrm{BOX})$ complexes, ${ }^{16,28-31}$ and these primarily focussed on the oxidation state of the $\mathrm{Cu}^{\mathrm{II}}$ ion, rather than the role of the counterion. One of the first groups to recognise how advanced EPR techniques can be used to probe these counterion $\left(\mathrm{TfO}^{-}, \mathrm{SbF}_{6}^{-}, \mathrm{Cl}^{-}, \mathrm{Br}^{-}\right)$effects for the related $\mathrm{Cu}^{\mathrm{II}}-$ bissulfoximine complexes in the Diels-Alder reaction was Bolm and Gescheidt. ${ }^{32,33}$ Therefore in the current investigation we describe the detailed characterisation of the paramagnetic $\mathrm{Cu}^{\mathrm{II}} \mathrm{BOX}$ complexes (shown in Scheme 1) using EPR and ENDOR spectroscopy, with specific emphasis on the influence of the counterion $\left(\mathrm{TfO}^{-}\right.$or $\mathrm{Cl}^{-}$) on the structure of the complex in solution.

\section{Experimental section}

\section{Chemicals and synthesis}

All reagents were purchased from Sigma Aldrich and used as received. The BOX ligand (labelled (1) in Scheme 1, (-)-2,2'Isopropylidenebis[(4S)-4-phenyl-2-oxazoline], CAS no. 13145746-0) was used as received. All reactions were performed under atmospheric conditions. The heteroleptic complexes [Cu $\left.{ }^{\mathrm{II}}(\mathbf{1} \mathbf{a}, \mathbf{c})\right]$ were prepared according to literature methods ${ }^{34}$ by reacting $\mathrm{Cu}^{\mathrm{II}}(\mathrm{OTf})_{2}$ or $\mathrm{Cu}^{\mathrm{II}} \mathrm{Cl}_{2}$ with (1) in tetrahydrofuran-dichloromethane (THF-DCM). The homoleptic complex, [Cu $\left.{ }^{\mathrm{II}}(\mathbf{1 b})\right]$, was synthesised by stirring (1) with $\mathrm{Cu}^{\mathrm{II}}(\mathrm{OTf})_{2}$ in THF for $1 \mathrm{~h}$ at room temperature. HR ES-MS for $\left[\mathrm{Cu}^{\mathrm{II}}(\mathbf{1 b})\right]$, found (calc. for C42H44CuN4O4): 731.2635 (731.2659).

\section{Spectroscopic measurements}

For CW and pulsed EPR/ENDOR measurements, the heteroleptic copper complexes [Cu $\left.{ }^{\mathrm{II}}(\mathbf{1 a}, \mathbf{c})\right]\left(c a .7 \times 10^{-3} \mathrm{M}\right.$ for EPR, ca. $4 \times 10^{-2} \mathrm{M}$ for ENDOR) were dissolved in either $\mathrm{d}^{8}$-tetrahydrofuran- $\mathrm{d}^{2}$-dichloromethane (abbreviated THF-DCM) or $\mathrm{d}^{3}-$ acetonitrile- $\mathrm{d}^{2}$-dichloromethane (abbreviated AcN-DCM) while the homoleptic complex $\left[\mathrm{Cu}^{\mathrm{II}}(\mathbf{1 b})\right]$ was dissolved in $\mathrm{d}^{3}$-acetonitrile- $\mathrm{d}^{2}$-dichloromethane (AcN-DCM). The choice of solvent considerably affected the solubility, where higher concentrations were required for the CW ENDOR measurements. All X-band EPR spectra were recorded on a Bruker EMX spectrometer operating at $100 \mathrm{kHz}$ field modulation and equipped with a high sensitivity X-band cavity (ER 4119HS). The spectra were recorded at a microwave power of $10 \mathrm{~mW}$ at $140 \mathrm{~K}$. The $\mathrm{CW}$ Q-band ENDOR spectra were recorded at $10 \mathrm{~K}$ on a CW Bruker ESP 300E series spectrometer equipped with an ESP360 DICE ENDOR unit, operating at $12.5 \mathrm{kHz}$ field modulation in a Q-band ENDOR cavity (Bruker ER 5106 QT-E). The ENDOR spectra were obtained using $8 \mathrm{~dB}$ RF power from an ENI A-300 RF amplifier and 50 or $200 \mathrm{kHz}$ RF modulation depth and $1 \mathrm{~mW}$ microwave power. The pulsed X-band EPR/ENDOR spectra were recorded on a Bruker Elexsys E580 spectrometer equipped with a liquid Helium cryostat from Oxford Inc. The spectra were taken at $10 \mathrm{~K}$, with a repetition rate of $333 \mathrm{kHz}$. The pulse sequence $\pi-T-\pi / 2-\tau-\pi-\tau$-echo was used for the Davies ENDOR measurements, using mw pulse lengths of $t_{\pi}=$ $256 \mathrm{~ns}, t_{\pi / 2}=128 \mathrm{~ns}$, and an interpulse time $\tau$ of $800 \mathrm{~ns}$. An rf $\pi$ pulse of variable frequency and a length of $18 \mu \mathrm{s}$ was applied during time $T$ of $20 \mu \mathrm{s}$. EPR simulations were performed using the Sim32 software, ${ }^{35}$ and ENDOR simulations were performed using the Easyspin package. $^{36}$

\section{DFT calculations}

The EPR parameters were calculated via spin-unrestricted density functional computations using the ORCA package ${ }^{37-40}$ on the reported crystal structures of $\left[\mathrm{Cu}^{\mathrm{II}}(\mathbf{1 a})\right]^{34}$ and $\left[\mathrm{Cu}^{\mathrm{II}}(\mathbf{1} \mathbf{c})\right]{ }^{14}$ The computations were performed with the B3LYP functional. Basis sets with significant flexibility in the core region were used (ORCA basis sets 'CoreProp' (CP(III) $)^{41}$ for copper, and a Barone basis set 'EPRII ${ }^{42}$ for the hydrogen atoms).

\section{Results and discussion}

\section{CW EPR of $\left[\mathrm{Cu}^{\text {II }}(\mathbf{1 a}-\mathrm{c})\right]$}

The $\mathrm{Cu}^{\mathrm{II}}(\mathrm{BOX})$ complexes are most conveniently prepared by simply stirring a suitable $\mathrm{Cu}^{\mathrm{II}}$ salt with the required BOX ligand in solution. The solvent and the $\mathrm{Cu}-\mathrm{BOX}$ ratio is then critical in order to form the desired $\mathrm{Cu}^{\mathrm{II}}(\mathrm{BOX})$ complex. This can be easily monitored by EPR spectroscopy, as shown in Fig. 1. A solution of ligand (1) in THF-DCM was stirred with $\mathrm{Cu}^{\mathrm{II}}(\mathrm{OTf})_{2}$ for $1 \mathrm{~h}$, and the resulting profile of the EPR spectra changes considerably as more of the $\mathrm{Cu}^{\mathrm{II}}(\mathrm{OTf})_{2}$ progressively coordinates with the BOX ligand (1). Fig. 1a shows the initial EPR spectrum of $\mathrm{Cu}^{\text {II }}(\mathrm{OTf})_{2}$ in the absence of (1), while Fig. 1b-e shows the resulting spectra after addition of increasing amounts of (1).

The pronounced superhyperfine couplings observed in Fig. 1b-e, are clearly indicative of $\mathrm{Cu}^{\mathrm{II}}$ coordination to (1). At a $\mathrm{Cu}-\mathrm{BOX}$ ratio of $1: 0.5$, a mixture of both $\mathrm{Cu}^{\mathrm{II}}(\mathrm{OTf})_{2}$ and a $\mathrm{Cu}^{\mathrm{II}}$ coordinated BOX complex is observed (Fig. 1b). At a $\mathrm{Cu}-$ $\mathrm{BOX}$ ratio of $1: 1$, a well resolved EPR spectrum is obtained, indicative of the formation of a single $\mathrm{Cu}^{\mathrm{II}}(\mathrm{BOX})$ complex. Finally, as the $\mathrm{Cu}-\mathrm{BOX}$ ratio increases further (i.e., $1: 2$ and $1: 6$, Fig. 1d,e), the shape of the spectra changes further, indicative of the formation of a second $\mathrm{Cu}^{\mathrm{II}}(\mathrm{BOX})$ type complex (1), vide infra). A similar series of EPR spectra can also be observed for the $\mathrm{Cu}^{\mathrm{II}} \mathrm{Cl}_{2}$ salt after reacting with (1) in DCM; see Fig. S1, ESI. $\dagger$ In order to understand the structure of the $\mathrm{Cu}^{\mathrm{II}}(\mathrm{BOX})$ complexes responsible for the spectra shown in Fig. 1b-e, additional 


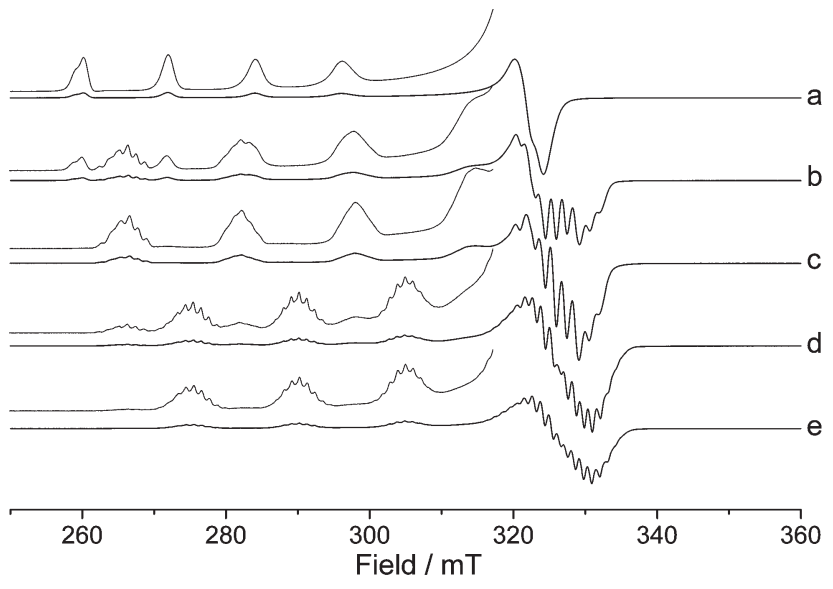

Fig. 1 X-band CW EPR spectra $(140 \mathrm{~K})$ of (a) $\mathrm{Cu}^{\mathrm{II}}(\mathrm{OTf})_{2}$ dissolved in THF-DCM, containing increasing $\mathrm{Cu}-\mathrm{BOX}$ (1) ratios; (b) $1: 0.5$, (c) $1: 1$, (d) $1: 2$ and (e) $1: 6$. Solvent system, $1: 1 \mathrm{THF}-\mathrm{DCM}$.

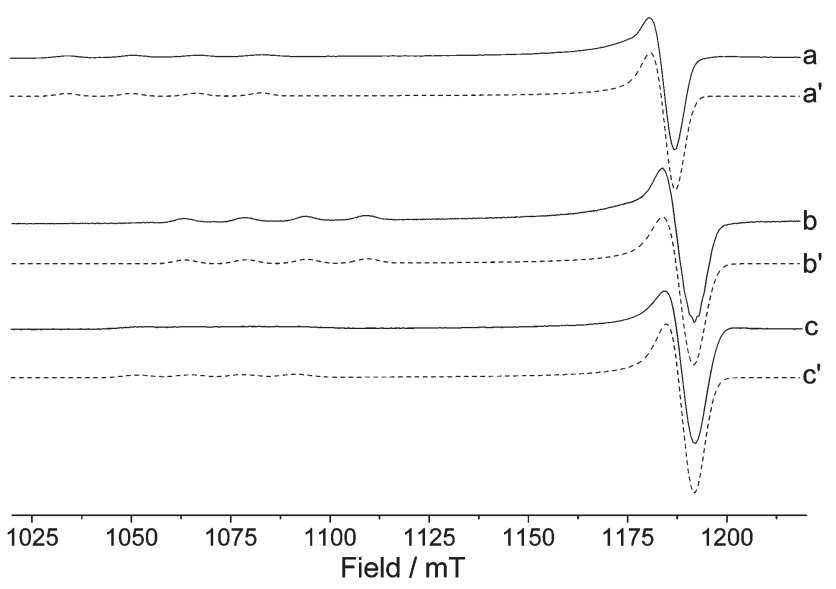

Fig. 2 Q-band CW EPR spectra $(50 \mathrm{~K})$ of (a) $\left[\mathrm{Cu}^{\mathrm{II}}(\mathrm{BOX})\right](\mathrm{OTf})_{2}$ $\left(\mathrm{Cu}-\mathrm{BOX}\right.$ ratio $1: 1$, in THF-DCM), (b) $\left[\mathrm{Cu}^{\mathrm{II}}(\mathrm{BOX})_{2}\right](\mathrm{Cu}-\mathrm{BOX}$ ratio $1: 6$, in $\mathrm{AcN}-\mathrm{DCM})$, and $(\mathrm{c})\left[\mathrm{Cu}^{\mathrm{II}}(\mathrm{BOX})\right](\mathrm{Cl})_{2}(\mathrm{Cu}-\mathrm{BOX}$ ratio $1: 1$, in THF-DCM). The corresponding simulations of these $\left[\mathrm{Cu}^{\mathrm{II}}(\mathbf{1} \mathbf{a})\right]$, $\left[\mathrm{Cu}^{\mathrm{II}}(\mathbf{1 b})\right]$ and $\left[\mathrm{Cu}^{\mathrm{II}}(\mathbf{1} \mathbf{c})\right]$ complexes are given in $\mathrm{a}^{\prime}-\mathrm{c}^{\prime}$.

Q-band EPR spectra were performed to aid in the simulations and analysis of the spin Hamiltonian parameters.

The Q-band CW EPR spectra for $\mathrm{Cu}^{\mathrm{II}}(\mathrm{OTf})_{2}$ and $\mathrm{Cu}^{\mathrm{II}} \mathrm{Cl}_{2}$ containing different ratios of $\mathrm{Cu}-\mathrm{BOX}$ ligand are given in Fig. 2 while the corresponding $\mathrm{X}$-band data is given in Fig. 3 along with the spectra of the starting $\mathrm{Cu}^{\mathrm{II}}(\mathrm{OTf})_{2}$ and $\mathrm{Cu}^{\mathrm{II}} \mathrm{Cl}_{2}$ salts for comparison. Since the $g$-strain effect is larger at Q-band compared to X-band frequency, the resolution of the hyperfine splitting is lost in the $g_{1,2}$ region of the spectrum. The spin Hamiltonian parameters were extracted by simulation of both the $\mathrm{X}$ - and Q-band data, and the resulting parameters are listed in Table 1 . The $g$ and $\boldsymbol{A}^{\mathrm{Cu}}$ tensors for the $\mathrm{Cu}^{\mathrm{II}}(\mathrm{OTf})_{2}$ and $\mathrm{Cu}^{\mathrm{II}} \mathrm{Cl}_{2}$ salts are both axially symmetric, and largely consistent with previous reports ${ }^{43,44}$ (it should be noted that the profile of these spectra are heavily solvent dependent). The EPR spectrum of $\mathrm{Cu}^{\mathrm{II}} \mathrm{Cl}_{2}$ (Fig. 3d) also contains a series of additional lines in the perpendicular region, which arise from the superhyperfine couplings to weakly interacting solvent molecules.

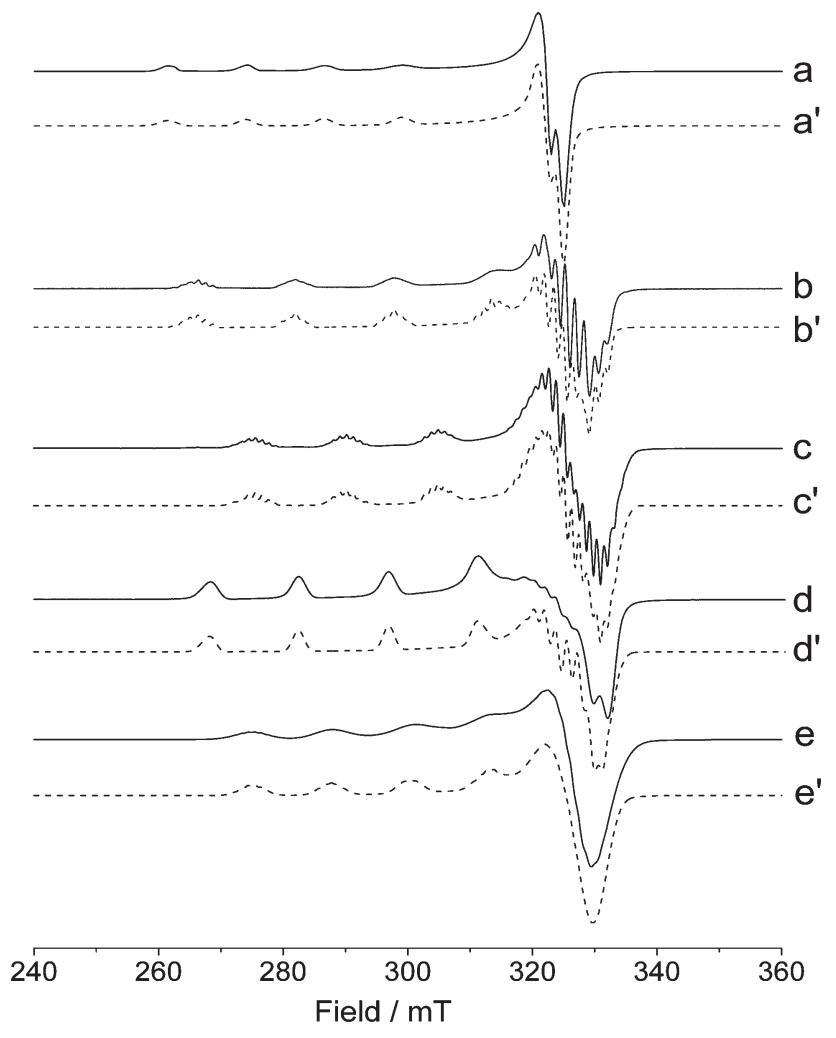

Fig. 3 X-band CW EPR spectra $(140 \mathrm{~K})$ of (a) $\mathrm{Cu}^{\mathrm{II}}(\mathrm{OTf})_{2}$, (b) $\left[\mathrm{Cu}^{\mathrm{II}}(\mathbf{1 a})\right](\mathrm{Cu}-\mathrm{BOX}$ ratio $1: 1),(\mathrm{c})\left[\mathrm{Cu}^{\mathrm{II}}(\mathbf{1 b})\right](\mathrm{Cu}-\mathrm{BOX}$ ratio $1: 6),(\mathrm{d})$ $\mathrm{Cu}^{\mathrm{II}}(\mathrm{Cl})_{2}$ and (e) $\left[\mathrm{Cu}^{\mathrm{II}}(\mathbf{1 c})\right](\mathrm{Cu}-\mathrm{BOX}$ ratio $1: 1)$ dissolved in $1: 1$ THF-DCM solvent. The corresponding simulations are given in $\mathrm{a}^{\prime}-\mathrm{e}^{\prime}$.

Table $1 \boldsymbol{g}$ and $\boldsymbol{A}^{\mathrm{Cu}}$ spin Hamiltonian parameters for the $\mathrm{Cu}^{\mathrm{II}}(\mathrm{BOX})$ complexes $\left[\mathrm{Cu}^{\mathrm{II}}(\mathbf{1} \mathbf{a}-\mathbf{c})\right]$ dissolved in THF-DCM and the initial $\mathrm{Cu}^{\text {II }}(\mathrm{OTf})_{2}$ and $\mathrm{Cu}^{\mathrm{II}} \mathrm{Cl}_{2}$ salts

\begin{tabular}{llllcrr}
\hline Complex & $g_{1}{ }^{a}$ & $g_{2}{ }^{a}$ & $g_{3}{ }^{a}$ & \multicolumn{1}{c}{$A_{1}{ }^{b}$} & \multicolumn{1}{c}{$A_{2}{ }^{b}$} & \multicolumn{1}{c}{$A_{3}{ }^{c}$} \\
\hline $\mathrm{Cu}(\mathrm{OTf})_{2}$ & 2.083 & 2.083 & 2.412 & 13.1 & 13.1 & 403.4 \\
$\mathrm{CuCl}{ }_{2}$ & 2.061 & 2.061 & 2.316 & 54.8 & 54.8 & 457.8 \\
{$[\mathrm{Cu}(\mathbf{1 a})]$} & 2.064 & 2.073 & 2.313 & 15.0 & 14.5 & 506.7 \\
$D F T$ & 2.069 & 2.073 & 2.209 & -32.85 & -44.6 & -866.5 \\
{$[\mathrm{Cu}(\mathbf{1 b})]$} & 2.054 & 2.063 & 2.254 & 25.9 & 28.9 & 461.3 \\
{$[\mathrm{Cu}(\mathbf{1 c})]$} & 2.057 & 2.057 & 2.280 & 33.1 & 33.1 & 395.7 \\
$D F T$ & 2.062 & 2.064 & 2.204 & -76.4 & -81.7 & -764.6
\end{tabular}

All $A$ values given in $\mathrm{MHz} ;{ }^{a} \pm 0.004 ;{ }^{b} \pm 3 \mathrm{MHz} ;{ }^{c} \pm 6 \mathrm{MHz}$.

The EPR spectra of the $\mathrm{Cu}^{\mathrm{II}}(\mathrm{BOX})$ complexes were simulated using slightly rhombic $\boldsymbol{g}$ and $\boldsymbol{A}^{\mathrm{Cu}}$ tensors (see Table 1). The resolved copper hyperfine splittings are further split due to the hyperfine interaction with two equivalent ${ }^{14} \mathrm{~N}$ nuclei in Fig. $3 \mathrm{~b}, \mathrm{e}$ and four equivalent ${ }^{14} \mathrm{~N}$ nuclei in Fig. 3c. The $g$ values used in the simulation were extracted more accurately from the Q-band spectra (Fig. 2). Although the $g_{1,2}$ regions of the X-band spectra are particularly complex, since the $\mathrm{Cu}$ and ${ }^{14} \mathrm{~N}$ hyperfine couplings are of similar magnitude (Table 1 ), accurate ${ }^{14} \mathrm{~N}$ couplings were determined via the ENDOR measurements (vide infra) and these parameters were used in the EPR simulations.

The $g_{3} / A_{3}$ values of $\mathrm{Cu}^{\mathrm{II}}$ complexes possessing a $d_{x^{2}-y^{2}}$ ground state, are usually diagnostic of the coordinating environment. ${ }^{45,46}$ 
Therefore the $g_{3} / A_{3}$ values of $2.313 / 506.7 \mathrm{MHz}$ and 2.280 / 395.7 MHz for the complexes responsible for Fig. 3b and e respectively, coupled with the observed hyperfine splittings from two equivalent ${ }^{14} \mathrm{~N}$, are consistent with the presence of the heteroleptic complexes labelled $\left[\mathrm{Cu}^{\mathrm{II}}(\mathrm{BOX})\right](\mathrm{OTf})_{2}$ and $\left[\mathrm{Cu}^{\mathrm{II}}(\mathrm{BOX})\right] \mathrm{Cl}_{2}$ (i.e., $\left[\mathrm{Cu}^{\mathrm{II}}(\mathbf{1 a})\right]$ and $\left[\mathrm{Cu}^{\mathrm{II}}(\mathbf{1} \mathbf{c})\right]$ in Scheme 1$)$. The altered $g_{3} / A_{3}$ values of $2.254 / 461.3 \mathrm{MHz}$ for the $\mathrm{Cu}^{\text {II }}$ complex represented by Fig. 3c, coupled with the four equivalent ${ }^{14} \mathrm{~N}$ nuclei clearly resolved in the low field $m_{\mathrm{I}}=-3 / 2 \mathrm{Cu}$ hyperfine line, are consistent with a coordinating environment bearing four equivalent nitrogens. This spectrum therefore provides evidence for the presence of the homoleptic complex $\left[\mathrm{Cu}^{\mathrm{II}}(\mathrm{BOX})_{2}\right]$ (i.e., $\left[\mathrm{Cu}^{\mathrm{II}}(\mathbf{1 b})\right]$ in Scheme 1) in solution at the higher $\mathrm{Cu}-\mathrm{BOX}$ ratios. Whilst homoleptic complexes of this type have been isolated, none have been crystallographically characterised. ${ }^{17}$

The spin Hamiltonian parameters determined for the two heteroleptic complexes $\left[\mathrm{Cu}^{\mathrm{II}}(\mathbf{1 a})\right]$ and $\left[\mathrm{Cu}^{\mathrm{II}}(\mathbf{1} \mathbf{c})\right]$ are notably different. This suggests that the counterions $\left(\mathrm{TfO}^{-}\right.$and $\left.\mathrm{Cl}^{-}\right)$must remain coordinated to the $\mathrm{Cu}^{\mathrm{II}}$ centre in solution, in order to alter the observed spin Hamiltonian parameters. Indeed ENDOR spectroscopy reveals the presence of ${ }^{19} \mathrm{~F}$ couplings from the $\mathrm{TfO}^{-}$groups, further confirming the presence of the counterion in the coordination sphere (vide infra). Moreover, the different $\boldsymbol{g} / \boldsymbol{A}$ values for $\left[\mathrm{Cu}^{\mathrm{II}}(\mathbf{1 a})\right]$ and $\left[\mathrm{Cu}^{\mathrm{II}}(\mathbf{1 c})\right]$ may in part be accounted for by differences in the distortion around the $\mathrm{Cu}^{\mathrm{II}}$ centre caused by the bulky triflate ions relative to the chlorides.

The above EPR results indicate that as the $\mathrm{Cu}-\mathrm{BOX}$ ratio increases, the heteroleptic and subsequently homoleptic $\mathrm{Cu}^{\mathrm{II}}$ bis (oxazoline) complexes are formed starting from the $\mathrm{Cu}^{\mathrm{II}}(\mathrm{OTf})_{2}$ salts (Fig. 1). The analogous trend is not however observed starting from the $\mathrm{CuCl}_{2}$ salt; regardless of the $\mathrm{Cu}-\mathrm{BOX}$ ratio employed, the homoleptic complex is never formed even when (1) is present in excess (see Fig. S1, ESI $\dagger$ ). In other words, the more labile $\mathrm{TfO}^{-}$counterions are easily displaced when an excess of (1) is present in solution, whereas the $\mathrm{Cl}^{-}$counterions remain more strongly coordinated, preventing coordination of a second BOX ligand.

\section{${ }^{14}$ N ENDOR}

In order to extract the hyperfine and nuclear quadrupole principal values of the ${ }^{14} \mathrm{~N}$ nuclei from the bis(oxazoline) ligand, X-band Davies ENDOR and Q-band CW ENDOR measurements were conducted on each sample $\left[\mathrm{Cu}^{\mathrm{II}}(\mathbf{1} \mathbf{a}-\mathbf{c})\right]$. The ENDOR spectra were measured at multiple field positions. The experimental spectra and corresponding simulations at the two frequencies for the heteroleptic $\left[\mathrm{Cu}^{\mathrm{II}}(\mathbf{1} \mathbf{a})\right]$ complex are shown in Fig. 4 (the simulated parameters are listed in Table 2). The relevant ENDOR spectra for the $\left[\mathrm{Cu}^{\mathrm{II}}(\mathbf{1} \mathbf{b}, \mathbf{c})\right]$ complexes are given in Fig. S2 and S3 in the ESI. $\uparrow$ The X-band Davies ENDOR spectra were obtained using soft mw pulses and therefore contain overlapping contributions from ${ }^{1} \mathrm{H},{ }^{19} \mathrm{~F}$ in addition to the strongly coupled ${ }^{14} \mathrm{~N}$ nuclei (Fig. 4A). Despite variations in the strength of the mw pulses (so-called hyperfine selective ENDOR),

Table $2{ }^{14} \mathrm{~N}$ hyperfine and quadrupole parameters for bis(oxazoline) nitrogens in the $\left[\mathrm{Cu}^{\mathrm{II}}(\mathbf{1} \mathbf{a}-\mathbf{c})\right]$ complexes. For comparison the ${ }^{14} \mathrm{~N}$ parameters for $\mathrm{Cu}^{\mathrm{II}}$ in an N2O2 (Cu-Salen) ${ }^{51}$ and $\mathrm{N} 4(\mathrm{Cu}$-porphyrin $=$ $\mathrm{CuPc})^{52}$ coordinating ligand environment are also given

\begin{tabular}{lcccccccc}
\hline Complex & $A_{1}{ }^{a}$ & $A_{2}$ & $A_{3}$ & $P_{1}{ }^{b}$ & $P_{2}$ & \multicolumn{1}{c}{$P_{3}$} & $\mathrm{e}^{2} \mathrm{qQ} / \mathrm{h}^{c}$ & $\eta^{d}$ \\
\hline$[\mathrm{Cu}($ Salen) $)]$ & 50.5 & 37.4 & 38.5 & -1.15 & 0.70 & 0.45 & -2.3 & 0.2 \\
{$[\mathrm{CuPc}]$} & 56.4 & 44.8 & 45.7 & -0.79 & 0.82 & 0.03 & & \\
{$[\mathrm{Cu}(\mathbf{1 a})]$} & 45.6 & 35.9 & 36.7 & -0.87 & 0.97 & -0.10 & -2.3 & 0.2 \\
{$[\mathrm{Cu}(\mathbf{1 b})]$} & 39.8 & 33.1 & 32.9 & -0.57 & 0.52 & 0.05 & & \\
{$[\mathrm{Cu}(\mathbf{1 c})]$} & 41.9 & 32.5 & 32.8 & -0.87 & 0.97 & -0.10 & -2.5 & 0.15
\end{tabular}

All values are given in $\mathrm{MHz} ;{ }^{a} \pm 0.2 \mathrm{MHz} ;{ }^{b} \pm 0.1 \mathrm{MHz} ;{ }^{c} \pm 0.2 \mathrm{MHz}$; ${ }^{d} \pm 0.1$.

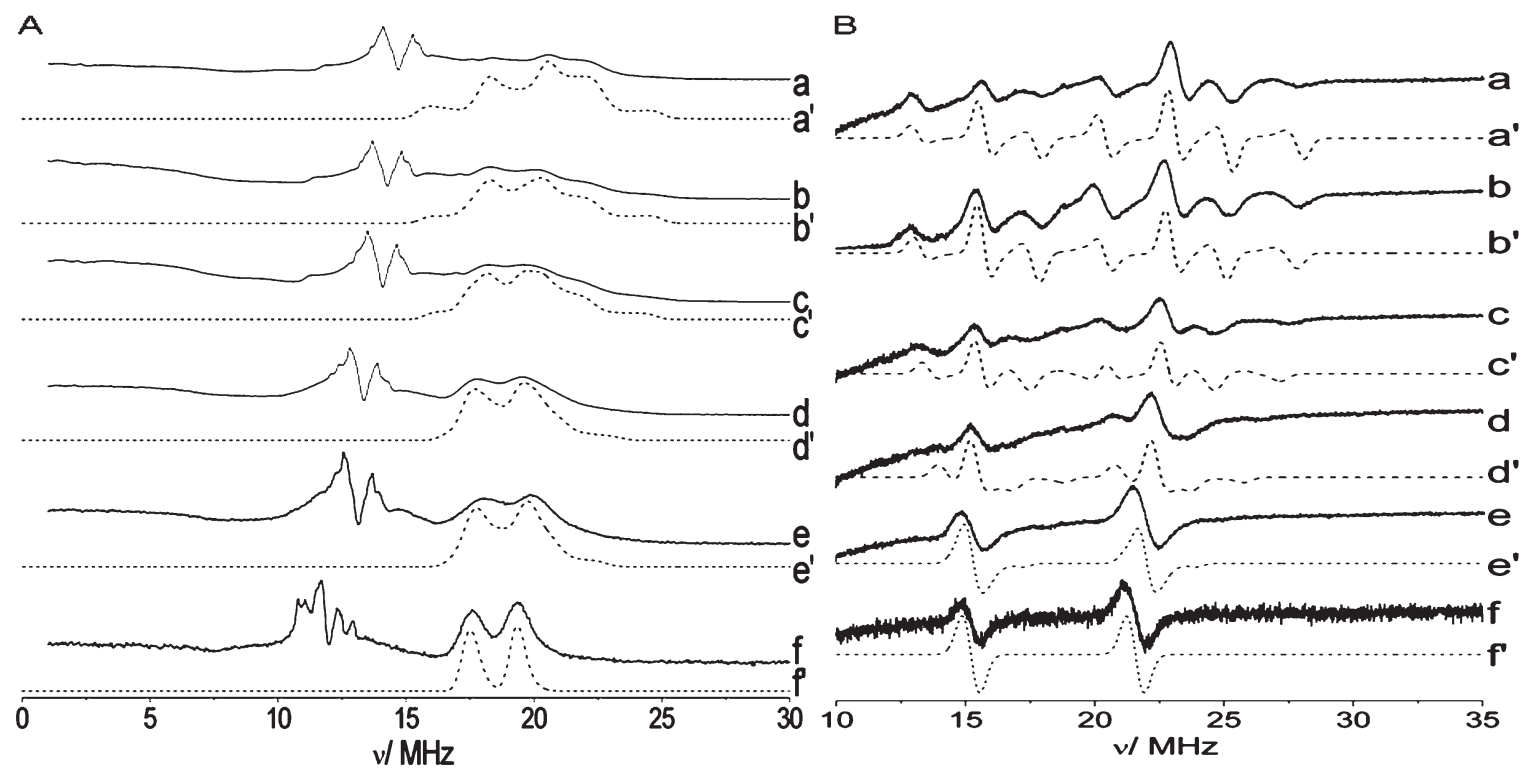

Fig. 4 (A) X-band Davies ENDOR spectra (10 K) of $[\mathrm{Cu}(\mathbf{1 a})]$ recorded at the field positions (a) 344.3, (b) 334.5, (c) 330.0, (d) 313.0, (e) 307.0 and (f) $280.6 \mathrm{mT}$. (B) Q-band $\mathrm{CW}{ }^{14} \mathrm{~N}$ ENDOR spectra (10 K) of $[\mathrm{Cu}(\mathbf{1 a})]$ recorded at the field positions (a) 1180.4, (b) 1176.9, (c) 1159.7, (d) 1124.4 , (e) 1080.0 and (f) $1030.8 \mathrm{mT}$. The corresponding simulations (for ${ }^{14} \mathrm{~N}$ only) are given in $\mathrm{a}^{\prime}-\mathrm{f}^{\prime}$. All spectra recorded in a $1: 1 \mathrm{THF}-\mathrm{DCM}$ solvent. 
complete suppression of the ${ }^{1} \mathrm{H}$ peaks could not be achieved, so these spectra remain significantly overlapped. Nevertheless the X-band Davies ENDOR spectra are important in order to observe the largest ${ }^{14} \mathrm{~N}$ couplings which can sometimes be difficult to detect via CW ENDOR.

The ${ }^{14} \mathrm{~N}$ couplings are in fact extremely well resolved at Q-band (Fig. 4B) enabling the angular selective data to be simulated more accurately (Table 2 ). The hyperfine and quadrupolar coupling from the ${ }^{14} \mathrm{~N}(I=1)$ nuclei in the $[\mathrm{Cu}(\mathbf{1 a})]$ complex was found to deviate slightly from axial symmetry and the largest principal axes was approximately directed to the copper ion. The observed hyperfine $\left(A_{i}\right)$ and quadrupolar $\left(P_{i}\right)$ parameters are very similar to those reported for other $\mathrm{Cu}^{\mathrm{II}}$ centres bearing strongly coupled N4 or N2O2 donor ligand sets (Table 2).

Whilst the quadrupolar ${ }^{14} \mathrm{~N}$ parameters are similar for the two heteroleptic complexes, $[\mathrm{Cu}(\mathbf{1 a})]$ and $[\mathrm{Cu}(\mathbf{1 c})]$, the hyperfine parameters are slightly different in each case. These differences in ${ }^{\mathrm{N}} \boldsymbol{A}_{i}$ are consistent with the earlier variations noted in the $\boldsymbol{g} /{ }^{\mathrm{Cu}} \boldsymbol{A}$ values by EPR (vide supra) and again suggest a slightly different degree of distortion in the $\mathrm{Cu}^{\mathrm{II}}-\mathrm{N} 2$ plane. An even larger difference in hyperfine $\left(A_{i}\right)$ and quadrupolar $\left(P_{i}\right)$ parameters is observed between the homoleptic $([\mathrm{Cu}(\mathbf{1 b})])$ and heteroleptic $([\mathrm{Cu}(\mathbf{1 a})])$ complexes (Table 2). In particular, the ${ }^{\mathrm{N}} A_{i}$ and ${ }^{\mathrm{N}} P_{i}$ parameters are smaller in the homoleptic complex (Table 2), and this is entirely consistent with the redistribution of the unpaired spin density in the $\mathrm{Cu}^{\mathrm{II}}-\mathrm{N} 4$ complex compared to the $\mathrm{Cu}^{\mathrm{II}}-\mathrm{N} 2$ complex.

\section{${ }^{1}$ H and ${ }^{19}$ F ENDOR}

The hyperfine couplings to the proton and fluorine nuclei of the complexes were well resolved by ENDOR at Q-band. The spectra recorded at the principal turning points $\left(g=g_{\|}\right.$and $\left.g=g_{\perp}\right)$ for $\left[\mathrm{Cu}^{\mathrm{II}}(\mathbf{1} \mathbf{a}-\mathbf{c})\right]$ are shown in Fig. 5. The presence of a weakly coupled ${ }^{19} \mathrm{~F}$ nucleus in $\left[\mathrm{Cu}^{\mathrm{II}}(\mathbf{1 a})\right]$ is evident in Fig. 5a,d, which must arise from coordinated $\mathrm{TfO}^{-}$groups. By comparison, in the homoleptic complex $\left[\mathrm{Cu}^{\mathrm{II}}(\mathbf{1 b})\right]$, only a matrix ${ }^{19} \mathrm{~F}$ peak centred on $v_{\mathrm{n}}$ for fluorine, is observed (Fig. 5b,e) and this emanates from remote (non-coordinated) $\mathrm{TfO}^{-}$ions in the surrounding solvent. The small ${ }^{19} \mathrm{~F}$ couplings in $\left[\mathrm{Cu}^{\mathrm{II}}(\mathbf{1 a})\right]$ produced a well resolved spectrum which was simulated at multiple field positions in order to extract the ${ }^{19} \mathrm{~F}$ hyperfine parameters (Fig. 6). The resulting ${ }^{\mathrm{F}} A$ hyperfine parameters are given in Table 3. Analysis of the ${ }^{\mathrm{F}} A$ data using a simple point dipole approximation suggests a $\mathrm{Cu} \cdots{ }^{19} \mathrm{~F}$ distance of $c a$. $7.78 \AA$ based on a dipolar coupling of $0.327 \mathrm{MHz}$. Furthermore the largest contribution to this coupling was observed along the $g=g_{\|}$ direction with an angle of $\theta_{\mathrm{H}}=0^{\circ}$ (angle between $g_{3}$ and $\mathrm{B}_{\mathrm{r}}$ ), consistent with the $\mathrm{TfO}^{-}$groups coordinating along the axial position of the $\mathrm{Cu}^{\mathrm{II}}$ complex (orthogonal to the $\mathrm{Cu}-\mathrm{N} 2$ plane). This picture is in fact consistent with the crystal structure of $\left[\mathrm{Cu}^{\mathrm{II}}(\mathbf{1})\right](\mathrm{OTf})_{2}\left(\mathrm{H}_{2} \mathrm{O}\right)_{2}$ reported by Evans et al., ${ }^{34}$ where the triflate groups were also oriented along the axial position. However the reported $\mathrm{Cu} \cdots \mathrm{F}$ distances varied from 4.834-6.049 $\AA$ in the crystal structure, ${ }^{34}$ compared to $7.78 \AA$ estimated by ENDOR. This large discrepancy must arise from the differences in counterion positioning in the solid state single crystal compared to the solvated complex in frozen solution, as

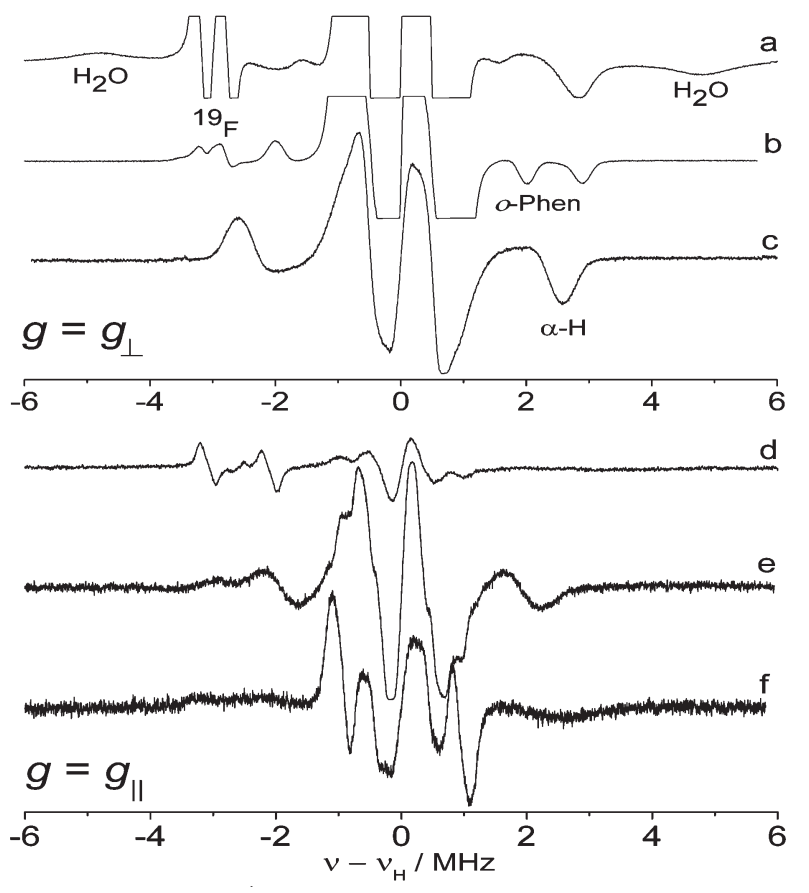

Fig. 5 Q-band $\mathrm{CW}{ }^{1} \mathrm{H}$ ENDOR spectra $(10 \mathrm{~K})$ of $(\mathrm{a}, \mathrm{d})[\mathrm{Cu}(\mathbf{1 a})](1: 1$ THF-DCM), (b,e) [Cu(1b)] (1:1 AcN-DCM) and (c,f) $[\mathrm{Cu}(\mathbf{1} \mathbf{c})](1: 1$ $\mathrm{AcN}-\mathrm{DCM})$. The spectra were recorded at the field positions corresponding to: $(\mathrm{a}, \mathrm{b}, \mathrm{c}) g=g_{\perp}$ and $(\mathrm{d}, \mathrm{e}, \mathrm{f}) g=g_{\|}$.

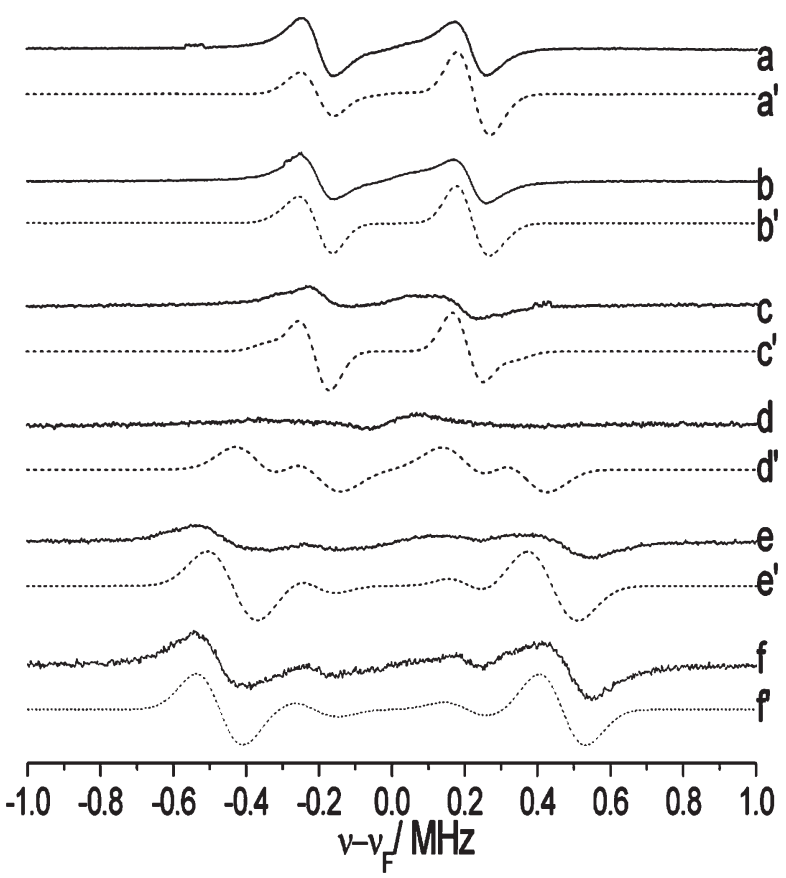

Fig. 6 Q-band $\mathrm{CW}{ }^{19} \mathrm{~F}$ ENDOR $(10 \mathrm{~K})$ of $\left[\mathrm{Cu}^{\mathrm{II}}(\mathbf{1 a})\right]$ dissolved in THF-DCM recorded at the field positions (a) 1180.4, (b) 1176.9, (c) 1159.7, (d) 1124.4 , (e) 1080.0 and (f) $1030.8 \mathrm{mT}$. The corresponding simulations are given in $\mathrm{a}^{\prime}-\mathrm{f}^{\prime}$. Solvent $1: 1 \mathrm{THF}-\mathrm{DCM}$.

measured by ENDOR; the presence of solvent molecules may then cause the $\mathrm{Cu} \cdots \mathrm{TfO}^{-}$distance to increase.

Furthermore the crystal structure of $\left[\mathrm{Cu}^{\mathrm{II}}(\mathbf{1})\right](\mathrm{OTf})_{2}\left(\mathrm{H}_{2} \mathrm{O}\right)_{2}$ notably contains two coordinated water molecules in the 
Table $3 \quad{ }^{1} \mathrm{H}$ and ${ }^{19} \mathrm{~F}$ principal hyperfine values for $[\mathrm{Cu}(\mathbf{1 a})]$. The DFT calculated parameters are also given

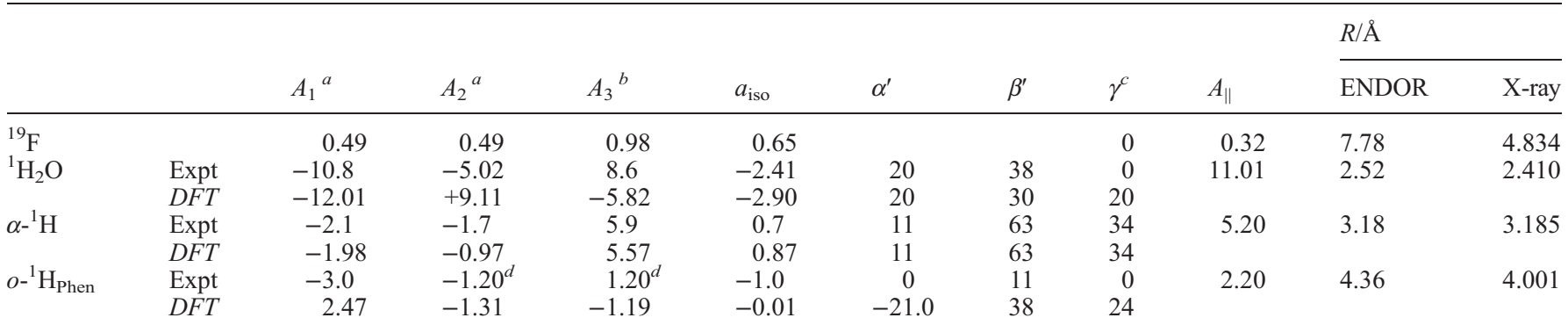

All values are given in $\mathrm{MHz} ;{ }^{a} \pm 0.2 \mathrm{MHz} ;{ }^{b} \pm 0.1 \mathrm{MHz} ;{ }^{c} \pm 10^{\circ} ;{ }^{d} \pm 0.5 \mathrm{MHz}$.

equatorial position. ${ }^{34}$ This is also consistent with the current ENDOR data for $[\mathrm{Cu}(\mathbf{1 a})]$ which reveals the presence of strongly coupled protons which are too large to arise from the ligand, and must therefore originate from bound water molecules. A large coupling of $c a$. $10 \mathrm{MHz}$ is observed in the experimental spectrum (Fig. 5a; $g=g_{\perp}$ position) which was not observed in either the homoleptic complex $[\mathrm{Cu}(\mathbf{1 b})]$ or in the heteroleptic complex formed from the $\mathrm{Cu}^{\mathrm{II}} \mathrm{Cl}_{2}$ salt, $[\mathrm{Cu}(1 \mathrm{c})]$ (Fig. 5b,c; $g=g_{\perp}$ position). We therefore tried to prepare the $[\mathrm{Cu}(\mathbf{1 a})]$ complex under rigorous anhydrous and anaerobic conditions, in order to suppress or eliminate the $\mathrm{H}_{2} \mathrm{O}$ derived peaks from the ENDOR spectra. Although a small suppression was observed, we could not completely eliminate the $\mathrm{H}_{2} \mathrm{O}$ peaks. This indicates that $\left[\mathrm{Cu}^{\mathrm{II}}(\mathbf{1})\right](\mathrm{OTf})_{2}$ prepared on the bench using commercially available $\mathrm{Cu}^{\text {II }}(\mathrm{OTf})_{2}$, is always likely to contain some coordinated water in solution.

The large couplings assigned to the bound water molecules in Fig. 5a, were simulated at multiple field positions and the resulting angular selective simulations are given in Fig. 7. Owing to the close proximity of the $\mathrm{H}_{2} \mathrm{O}$ to the $\mathrm{Cu}{ }^{\mathrm{II}}$ centre $\left(\mathrm{Cu} \cdots \mathrm{H}_{\mathrm{H} 2 \mathrm{O}}\right.$ distance of $2.410 \AA$ from the crystal structure), a large $a_{\text {iso }}$ contribution is expected (Table 3). Furthermore, analysis of the experimental hyperfine tensor suggests a $\mathrm{Cu} \cdot \cdots \mathrm{H}_{\mathrm{H} 2 \mathrm{O}}$ distance of $2.52 \AA\left(A_{\text {dipolar }}=11 \mathrm{MHz}\right)$, which is in reasonable agreement with the crystal structure.

The remaining proton couplings observed in the ENDOR spectra (Fig. 5 and 7) arise from the BOX ligand nuclei. In particular the nearest neighbour protons which interact with $\mathrm{Cu}^{\mathrm{II}}$ arise from the $\alpha-\mathrm{H}$ at the asymmetric carbon of the BOX ring (labelled $*$ in Scheme 1), with a $\mathrm{Cu} \cdots \alpha-\mathrm{H}_{\mathrm{BOX}}$ distance of $3.185 \AA$, and from the ortho- ${ }^{1} \mathrm{H}$ of the phenyl ring, with a $\mathrm{Cu} \cdots o-\mathrm{H}_{\text {phenyl }}$ distance of $4.001 \AA$. These two protons are most likely responsible for the observed couplings at $A_{1}=3.0 \mathrm{MHz}$ and 5.9 MHz in Fig. 5a-c. The principal hyperfine values for the $\alpha-\mathrm{H}$ are given in Table 3 , with an estimated $\mathrm{Cu} \cdots \alpha-\mathrm{H}_{\mathrm{BOX}}$ distance of $3.18 \AA$, in good agreement with the X-ray data. Unfortunately, owing to the overlapping features with the more remote protons from the BOX ligand, a reliable estimation of the $A_{2,3}$ components of the $o-\mathrm{H}_{\text {phenyl }}$ is not possible, hence the large difference in $\mathrm{Cu} \cdots o-\mathrm{H}_{\text {phenyl }}$ distances between the ENDOR data versus the X-ray data (Table 3).

\section{DFT calculations}

The spin Hamiltonian parameters were also calculated for the $\left[\mathrm{Cu}^{\mathrm{II}}(\mathbf{1 a})\right]$ and $\left[\mathrm{Cu}^{\mathrm{II}}(\mathbf{1 c})\right]$ complex in order to compare to the

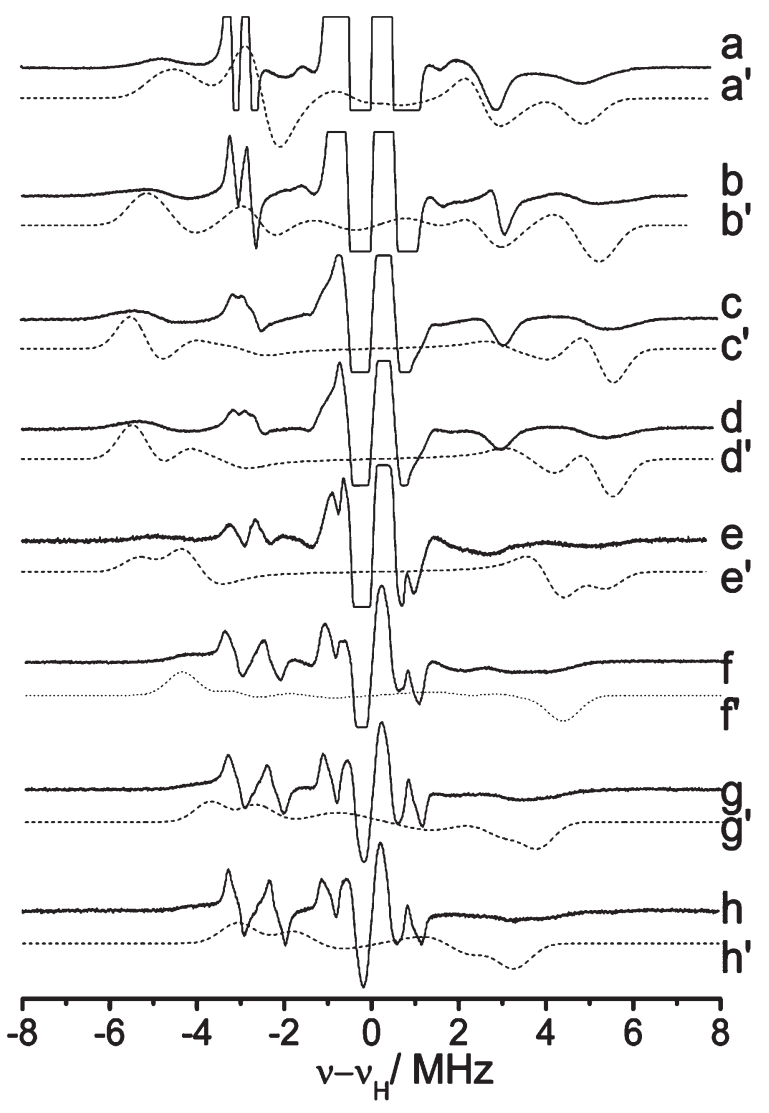

Fig. 7 Q-band $\mathrm{CW}{ }^{1} \mathrm{H}$ ENDOR $(10 \mathrm{~K})$ of $\left[\mathrm{Cu}^{\mathrm{II}}(\mathbf{1 a})\right]$ dissolved in THF-DCM recorded at the field positions (a) 1180.4, (b) 1176.9, (c) 1159.7, (d) 1124.4 , (e) 1080.0 and (f) $1030.8 \mathrm{mT}$. The corresponding simulations are given in $\mathrm{a}^{\prime}-\mathrm{h}^{\prime}$. Solvent $1: 1$ THF-DCM.

experimental data. The calculations were performed using the ORCA package ${ }^{37-40}$ and based on the reported crystal structures of $\left[\mathrm{Cu}^{\mathrm{II}}(\mathbf{1})\right](\mathrm{OTf})_{2}\left(\mathrm{H}_{2} \mathrm{O}\right)_{2}{ }^{34}$ and $\left[\mathrm{Cu}^{\mathrm{II}}(\mathbf{1})\right](\mathrm{Cl})_{2}{ }^{14}$ The relevant EPR parameters are listed in Tables 1 and 3. Current state-of-theart DFT methods still struggle to reproduce accurately the $g$ and metal hyperfine values for the transition metal ions, ${ }^{47}$ hence the discrepancy between the experimental and calculated $g /{ }^{\mathrm{Cu}} \boldsymbol{A}$ values in Table 1. Nevertheless, the general trends are in good agreement with each other. In particular the decrease in $g_{3}$ and $A_{3}$ observed experimentally upon complex formation is satisfactorily reproduced in the computations. Indeed the structure of the 
$\left[\mathrm{Cu}^{\mathrm{II}}(\mathbf{1})\right](\mathrm{Cl})_{2}$ complex used in the calculation had a slight twisted arrangement around the $\mathrm{Cu}-\mathrm{N} 2 \mathrm{Cl} 2$ plane, in agreement with the earlier EPR observations.

Ligand hyperfine parameters are more reliably determined by DFT, particularly for weakly coupled protons (Table 3). As expected the coordinated $\mathrm{H}_{2} \mathrm{O}$ molecules are predicted to produce the largest couplings, and these values are in good agreement with the experimental ENDOR data. The $\alpha-\mathrm{H}$ and ortho-phenyl protons of the BOX ligand also produce appreciable hyperfine couplings (Table 3 ). Although the $A_{1,2}$ couplings of these protons could not be confidently extracted from the powder ENDOR spectra, the largest calculated $A_{1}$ component agrees well with the experimental values (Table 3).

\section{Role of the counterion in $\mathrm{Cu}^{\mathrm{II}} \mathrm{BOX}$ complexes}

As stated earlier, the $\mathrm{Cu}^{\mathrm{II}}$ bis(oxazoline) complexes are used in a variety of different asymmetric reactions, including the DielsAlder reaction, ${ }^{7-16}$ cyclopropanation, ${ }^{17-20}$ and aziridination. ${ }^{21-23}$ In most cases, the metal based catalysts are prepared in situ by mixing the metal salt and BOX ligands prior to catalysis. Depending on the type and amount of BOX ligand used, and the nature of the counterion, this may result in the formation of a heteroleptic or homoleptic complex, such as $\left[\mathrm{Cu}^{\mathrm{II}}(\mathbf{1 a})\right]$ or $\left[\mathrm{Cu}^{\mathrm{II}}(\mathbf{1 b})\right]$ respectively, and this has important implications in catalysis. An excess of the BOX ligand clearly increases the likelihood of the formation of a homoleptic complex. However, as the current results show, this is heavily dependent on the choice of counterion. The more labile $\mathrm{TfO}^{-}$facilitates the formation of $\left[\mathrm{Cu}^{\mathrm{II}}(\mathbf{1 b})\right]$ when $\mathrm{BOX}$ is present in excess $(\mathrm{Cu}-\mathrm{BOX}$ ratio $1: 6)$, whereas the $\mathrm{Cl}^{-}$prevents this from occurring; only the heteroleptic complex $\left[\mathrm{Cu}^{\mathrm{II}}(\mathbf{1} \mathbf{c})\right]$ is observed under analogous preparative conditions.

The change in catalytic activity between the hetero- and homoleptic $\mathrm{Cu}^{\mathrm{II}} \mathrm{BOX}$ complexes have been explored by Hager et al. ${ }^{48}$ Competitive experiments were performed to monitor the yields and ee's, which demonstrated that the homoleptic complex was catalytically inactive. These complexes therefore required prolonged reaction times, and significantly lower yields were observed in these cases. Indeed Le Roux et al., ${ }^{49}$ highlighted the necessity for controlled synthesis conditions (slow addition of ligand to metal, under dilute metal concentrations) to prevent the formation of homoleptic complexes. Attempts have therefore been made to increase the steric bulk of the bis(oxazoline) ligand in order to prevent formation of the homoleptic species, ${ }^{49}$ whereas the current work reveals a change in counterion may also achieve a similar result.

Currently most of the catalysis work involving Lewis metal based bis(oxazoline) complexes have utilised $\mathrm{OTf}^{-}(\mathrm{OTf}=$ $\left.\mathrm{CF}_{3} \mathrm{SO}_{3}\right)$ or $\mathrm{SbF}_{6}$ counterions. For enantioselective aziridination using $\mathrm{Cu}^{\mathrm{II}}$ bis(oxazoline), Evans et al., ${ }^{21}$ reported that the $\mathrm{Cu}^{\mathrm{II}} \mathrm{Cl}_{2}$ and $\mathrm{Cu}^{\mathrm{II}} \mathrm{Br}_{2}$ salts were prohibitively slow with poor enantioselectivities, so that a highly electronegative counterion is a design prerequisite for efficient asymmetric catalysis. Fraile et al., ${ }^{26}$ postulated that the choice of counterion can affect the nature of the reaction mechanism, leading to undesired side-reactions that are non-asymmetric resulting in lower ee's. Furthermore, it is well known that the geometry of the $\mathrm{Cu}^{\mathrm{II}} \mathrm{BOX}$ complex, which is heavily dependent on the counterion, affects the catalysis. ${ }^{50}$ For example, when triflate is utilized as the counterion the X-ray crystal structure of the resulting $\mathrm{Cu}^{\mathrm{II}} \mathrm{BOX}$ complex reveals a Jahn-Teller distorted octahedral complex with $\mathrm{TfO}^{-}$coordinated in axial positions and water coordinated in the equatorial plane. By contrast, when $\mathrm{Cu}^{\mathrm{II}} \mathrm{Cl}_{2}$ is employed as the starting salt, the resulting complex exhibits a distorted squareplanar geometry with two chloride counterions coordinated to the metal center at $\sim 33^{\circ}$ out of the copper-ligand plane. Furthermore, the presence of the coordinating water molecules affects the direction of approach of substrates to the metal center, resulting in differences in enantioselectivity. As the current results reveal, these changes to the $\mathrm{Cu}^{\mathrm{II}} \mathrm{BOX}$ complexes induced by the different counterions can be examined by EPR and ENDOR techniques.

Bolm et al., ${ }^{32,33}$ previously reported the influence of the counterion and choice of starting metal salt for Diels-Alder reactions using the structurally similar $\mathrm{Cu}^{\mathrm{II}}$ bis(sulfoximine) complexes. The EPR spectra of the copper-bissulfoximine complexes showed significant differences depending on the starting $\mathrm{Cu}^{\mathrm{II}}$ salt $\left(\mathrm{CuCl}_{2}, \mathrm{CuBr}_{2}, \mathrm{Cu}(\mathrm{OTf})_{2}\right.$ and $\left.\mathrm{CuCl}_{2}-\mathrm{AgSbF}_{6}\right)$. Upon subsequent addition of a substrate molecule, ( $N$-(1-oxoprop-2-en-1yl)oxazolidin-2-one, changes were observed in the spectra, with distinct behaviour noted for the different counterions showing again how EPR can be successfully used to monitor such reactions. We are currently studying the mechanistic details involving these homo- and heteroleptic BOX complexes with $\mathrm{CuCl}_{2}$, $\mathrm{Cu}(\mathrm{OTf})_{2}$ and $\mathrm{CuCl}_{2}-\mathrm{AgSbF}_{6}$ for asymmetric aziridination and Diels-Alder reactions.

\section{Conclusions}

In the current study we have presented a detailed EPR and ENDOR investigation of a series of heteroleptic and homoleptic copper bis(oxazoline) complexes, [Cu $\left.{ }^{\text {II }}(\mathbf{1 a}-\mathbf{c})\right]$. The geometry of the hetereoleptic complexes $\left[\mathrm{Cu}^{\mathrm{II}}(\mathbf{1 a})\right]$ and $\left[\mathrm{Cu}^{\mathrm{II}}(\mathbf{1 c})\right]$ is dependent on the choice of counterion used in the synthesis, since different $\boldsymbol{g} /{ }^{\mathrm{Cu}} \boldsymbol{A}$ parameters are observed by EPR. Since the geometry is closely linked to the resulting catalytic activity, this work reveals the potential of EPR to study such complexes in solution. The homoleptic complex $\left[\mathrm{Cu}^{\mathrm{II}}(\mathbf{1} \mathbf{b})\right]$ was only formed using an excess of the BOX ligand (1) in the presence of the $\mathrm{Cu}^{\mathrm{II}}(\mathrm{OTf})_{2}$ salt; the $\mathrm{Cu}^{\mathrm{II}} \mathrm{Cl}_{2}$ salt prevented this from occurring. The hyperfine technique of ENDOR enabled the hyperfine and quadrupole parameters of the surrounding nuclei to be determined. Significant differences were observed in the ${ }^{\mathrm{N}} A$ values for $\left[\mathrm{Cu}^{\mathrm{II}}(\mathbf{1} \mathbf{a})\right]$ and $\left[\mathrm{Cu}^{\mathrm{II}}(\mathbf{1} \mathbf{c})\right]$, consistent with the more distorted arrangement in the latter complex, whereas smaller ${ }^{\mathrm{N}} A$ and ${ }^{\mathrm{N}} P$ values were detected for $[\mathrm{Cu}(\mathbf{1 b})]$ attributed to the redistributed spin density in the homoleptic complex. Well resolved ${ }^{19} \mathrm{~F}$ couplings in $\left[\mathrm{Cu}^{\mathrm{II}}(\mathbf{1 a})\right]$ confirmed the presence of coordinated $\mathrm{TfO}^{-}$ counterions along the axial direction, while strong ${ }^{1} \mathrm{H}$ couplings from bound water molecules along the equatorial direction were also observed for this complex. These results reveal how the inner and indeed outersphere coordination environment of $\mathrm{Cu}^{\mathrm{II}} \mathrm{BOX}$ complexes, of relevance to catalysis, can be studied by EPR and ENDOR in the 'solvated' environment where counterion effects are still manifested. 


\section{Acknowledgements}

Funding from EPSRC (EP/H023879) is gratefully acknowledged.

\section{References}

1 T. Katsuki and K. B. Sharpless, J. Am. Chem. Soc., 1980, 102, 5974-5976.

2 M. Movassaghi and E. N. Jacobsen, Science, 2002, 298, 1904-1905.

3 T. P. Yoon and E. N. Jacobsen, Science, 2003, 299, 1691-1693.

4 P. J. Walsh and M. C. Kozlowsk, Fundamentals of Asymmetric Catalysis, University Science Books, 2009.

5 A. K. Ghosh, P. Mathivanan and J. Cappiello, Tetrahedron: Asymmetry, $1998,9,1-45$.

6 J. M. Fraile, J. I. García and J. A. Mayoral, Coord. Chem. Rev., 2008, 252, 624-646.

7 D. A. Evans, S. J. Miller and T. Lectka, J. Am. Chem. Soc., 1993, 115, 6460-6461.

8 M. Johannsen and K. Anker Jørgensen, J. Chem. Soc., Perkin Trans. 2, 1997, 1183-1186.

9 D. A. Evans, S. J. Miller, T. Lectka and P. von Matt, J. Am. Chem. Soc., 1999, 121, 7559-7573.

10 D. A. Evans, D. M. Barnes, J. S. Johnson, T. Lectka, P. von Matt, S. J. Miller, J. A. Murry, R. D. Norcross, E. A. Shaughnessy and K. R. Campos, J. Am. Chem. Soc., 1999, 121, 7582-7594.

11 D. A. Evans, J. S. Johnson, C. S. Burgey and K. R. Campos, Tetrahedron Lett., 1999, 40, 2879-2882.

12 D. A. Evans, J. S. Johnson and E. J. Olhava, J. Am. Chem. Soc., 2000, 122, 1635-1649.

13 V. K. Aggarwal, D. E. Jones and A. M. Martin-Castro, Eur. J. Org Chem., 2000, 2939-2945.

14 J. Thornhauge, M. Roberson, R. G. Hazell and K. A. Jorgensen, Chem.-Eur. J., 2002, 8, 1888-1898.

15 A. Landa, B. Richter, R. L. Johansen, A. Minkkilä and K. A. Jørgensen, J. Org. Chem., 2007, 72, 240-245.

16 S. Tanaka, M. Tada and Y. Iwasawa, J. Catal., 2007, 245, 173-183.

17 R. E. Lowenthal, A. Abiko and S. Masamune, Tetrahedron Lett., 1990, 31, 6005-6008.

18 D. A. Evans, K. A. Woerpel, M. M. Hinman and M. M. Faul, J. Am. Chem. Soc., 1991, 113, 726-728.

19 A. M. Harm, J. G. Knight and G. Stemp, Tetrahedron Lett., 1996, 37, 6189-6192.

20 M. J. Fernández, J. M. Fraile, J. I. García, J. A. Mayoral, M. I. Burguete, E. García-Verdugo, S. V. Luis and M. A. Harmer, Top. Catal., 2000, 13, 303-309.

21 D. A. Evans, M. M. Faul, M. T. Bilodeau, B. A. Anderson and D. M. Barnes, J. Am. Chem. Soc., 1993, 115, 5328-5329.

22 C. Langham, P. Piaggio, P. McMorn, D. J. Willock, G. J. Hutchings, D. Bethell, D. F. Lee, P. C. Bulman Page, C. Sly, F. E. Hancock and F. King, Chem. Commun., 1998, 1601-1602.
23 C. Langham, D. Bethell, D. F. Lee, P. McMorn, P. C. Bulman Page, D. J. Willock, C. Sly, F. E. Hancock, F. King and G. J. Hutchings, Appl. Catal., A, 1999, 182, 85-89.

24 G. Desimoni, G. Faita and K. A. Jørgensen, Chem. Rev., 2006, 106, 3561-3651.

25 H. A. McManus and P. J. Guiry, Chem. Rev., 2004, 104, 4151-4202.

26 J. M. Fraile, J. I. García, J. A. Mayoral and T. Tarnai, J. Mol. Catal. A: Chem., 1999, 144, 85-89.

27 D. A. Evans, J. A. Murry, P. von Matt, R. D. Norcross and S. J. Miller, Angew. Chem., Int. Ed. Engl., 1995, 34, 798-800.

28 D. A. Evans, M. C. Kozlowski, C. S. Burgey and D. W. C. MacMillan, J. Am. Chem. Soc., 1997, 119, 7893-7894.

29 P. J. Alonso, J. M. Fraile, J. García, J. I. García, J. I. Martínez, J. A. Mayoral and M. C. Sánchez, Langmuir, 2000, 16, 5607-5612.

30 Y. Traa, D. M. Murphy, R. D. Farley and G. J. Hutchings, Phys. Chem. Chem. Phys., 2001, 3, 1073-1080.

31 V. Caplar, Z. Raza, M. Roje, V. Tomisic, G. Horvat, J. Pozar, I. Piantanida and M. Zinic, Tetrahedron, 2004, 60, 8079-8087.

32 C. Bolm, M. Martin, G. Gescheidt, C. Palivan, D. Neshchadin, H. Bertagnolli, M. Feth, A. Schweiger, G. Mitrikas and J. Harmer, J. Am. Chem. Soc., 2003, 125, 6222-6227.

33 C. Bolm, M. Martin, G. Gescheidt, C. Palivan, T. Stanoeva, H. Bertagnolli, M. Feth, A. Schweiger, G. Mitrikas and J. Harmer, Chem.-Eur. J., 2007, 13, 1842-1850.

34 D. A. Evans, C. S. Burgey, N. A. Paras, T. Vojkovsky and S. W. Tregay, J. Am. Chem. Soc., 1998, 120, 5824-5825.

35 T. Spalek, P. Pietrzyk and Z. Sojka, J. Chem. Inf. Model., 2005, 45, 1829.

36 S. Stoll and A. Schweiger, J. Magn. Reson., 2006, 178, 42-55.

37 F. Neese, J. Chem. Phys., 2001, 115, 11080-11096.

38 F. Neese, J. Phys. Chem. A, 2001, 105, 4290-4299.

39 F. Neese, J. Chem. Phys., 2003, 118, 3939-3948.

40 F. Neese, J. Chem. Phys., 2005, 122, 034107-034113.

41 This basis is based on the TurboMole DZ basis developed by Ahlrichs and co-workers and obtained from the basis set library under ftp.chemie. uni-karlsruhe.de/pub/basen, R. Ahlrichs and co-workers (unpublished).

42 V. Barone, Recent Advances in Density Functional Methods, World Scientific Publ. Co., Singapore, 1996.

43 H. R. Gersmann and J. D. Swalen, J. Chem. Phys., 1962, 36, 3221-3233.

44 N. Niklas and R. Alsfasser, Dalton Trans., 2006, 3188-3199.

45 W. E. B. J. Peisach, Arch. Biochem. Biophys., 1974, 165, 691-708.

46 J. R. Pilbrow, Transition Ion Electron Paramagnetic Resonance, Oxford Science Publications, Oxford University Press, 1st edn, 1990.

47 F. Neese, JBIC, J. Biol. Inorg. Chem., 2006, 11, 702-711.

48 M. Hager, S. Wittmann, A. Schätz, F. Pein, P. Kreitmeier and O. Reiser, Tetrahedron: Asymmetry, 2010, 21, 1194-1198.

49 E. Le Roux, N. Merle and K. W. Tornroos, Dalton Trans., 2011, 40, $1768-1777$.

50 K. A. Jørgensen, M. Johannsen, S. Yao, H. Audrain and J. Thorhauge, Acc. Chem. Res., 1999, 32, 605-613.

51 D. M. Murphy, I. Caretti, E. Carter, I. A. Fallis, M. C. Göbel, J. Landon, S. V. Doorslaer and D. J. Willock, Inorg. Chem., 2011, 50, 6944-6955.

52 C. Finazzo, C. Calle, S. Stoll, S. Van Doorslaer and A. Schweiger, Phys. Chem. Chem. Phys., 2006, 8, 1942-1953. 